\title{
Perilaku Pengguna Jasa Karantina Pertanian dalam Mendukung Perlindungan Sumberdaya Alam Hayati
}

\section{Agricultural Quarantine User Behavior in Supporting Protection Natural Resources Biodiversity}

\author{
Ririn Setyowati ${ }^{a}$, Akhmad Fauzi ${ }^{\text {b }}$ Eko S. Pribadic ${ }^{\text {, Hari Wijayanto }}{ }^{\mathrm{d}}$ \\ ${ }^{a}$ Mahasiswa Pascasarjana Ilmu Pengelolaan Sumberdaya Alam dan Lingkungan, Institut Pertanian Bogor, Kampus IPB \\ Baranangsiang, Bogor 16144 \\ ${ }^{\mathrm{b}}$ Departemen Ilmu Perencanaan Pembangunan Wilayah dan Pedesaan, Fakultas Ekonomi dan Manajemen, Institut Pertanian Bogor, \\ Kampus IPB Darmaga, Bogor 16680 \\ ${ }^{\mathrm{c}}$ Fakultas Kedokteran Hewan, Institut Pertanian Bogor, Kampus IPB Darmaga, Bogor 16680 \\ ${ }^{\mathrm{d}}$ Departemen Statistik, Fakultas Matematika dan IPA, Institut Pertanian Bogor, Kampus IPB Baranangsiang, Bogor 16144
}

\section{Article Info:}

Received: 26 - 01 - 2018

Accepted: 09 - 02 - 2018

Keywords:

Quarantine, user satisfaction, perception, participation, compliance.

Corresponding Author: Ririn Setyowati

Pascasarjana Ilmu Pengelolaan Sumberdaya Alam dan

Lingkungan, Institut Pertanian

Bogor, Kampus IPB

Baranangsiang, Bogor;

Email:

setyowati.ririn@gmail.com

\begin{abstract}
Agricultural quarantine is the forefront of Indonesia's natural biodiversity and technical barrier in agricultural commodities trade. This study aimed to analyze the user behavior of service users in utilizing agricultural quarantine services in relation to supporting the protection of natural resources biodiversity. This study used primary data, with purpossive random sampling as the sampling technique. Multiple regression analysis, Customer Satisfaction Index (CSI), and Structural Equation Modelling(SEM) were carried on this study. Through CSI calculation obtains the CSI value is $78.26 \%$ at satisfied range.The result of multiple re-gression analysis test indicated that emphaty, responsiveness, reliability, assurance, and tangible have significant influence to service user satisfaction. Hypothesis testing using SEM so that it is known that the perception and service quality have significant influence on user behavior characterized by participation and compliance level. By knowing the level of participation and compli-ance of service users is useful in determining and formulating strategies to increase protection of natural resources biodiversity through quarantine action.
\end{abstract}

How to cite (CSE Style $8^{\text {th }}$ Edition):

Setyowati R, Fauzi A, Pribadi ES, Wijayanto H. Perilaku pengguna jasa karantina pertanian dalam mendukung perlindungan sumberdaya alam hayati. JPSL 9(3): 577-586. http://dx.doi.org/10.29244/jps1.9.3.577-586.

\section{PENDAHULUAN}

Indonesia adalah negara yang kaya akan berbagai jenis sumberdaya alam hayati berupa aneka ragam jenis spesies hewan, ikan dan tumbuhan serta memiliki konsentrasi endemisme dan keragaman habitat yang tinggi sehingga menjadi salah satu megadiversity country. Letak Indonesia sebagai salah satu kawasan yang terletak didaerah tropis merupakan habitat bagi hewan dan tumbuhan untuk hidup dan berkembang biak. Mittermeier et al. (1997) menyebutkan bahwa Indonesia tergolong negara megadiversitas yang memiliki kekayaan hayati tertinggi kedua setelah Brasil. Dalam hal keanekaragaman jenis, Indonesia juga menjadi salah satu pusat keanekaragaman tanaman ekonomi dunia. Jenis-jenis kayu perdagangan, buah-buahan tropis, anggrek, bambu, rotan, kelapa dan lain-lain sebagian besar berasal dari Indonesia. Oleh karena itu Indonesia selain dikenal sebagai negara dengan keanekaragaman hayati terbesar (megadiversity country), Indonesia juga merupakan pusat keanekaragaman hayati dunia (megacenter of biodiversity) (Mac Kinnon 1992).Predikat sebagai negara megadiversitas, baik dari segi keanekaragaman ekosistem, keanekaragaman spesies dan keanekaragaman 
genetik menuntut tanggung jawab yang besar untuk pelestarian dan pemanfaatan bagi masyarakat. Tantangan terbesar dalam pengelolaan keanekaragaman hayati adalah mempertahankan keseimbangan antara kelestarian fungsi (ekologis) dengan kelestarian manfaat (ekonomis). Menurut Kusmana dan Hikmat (2015) Negara Indonesia termasuk negara dengan tingkat keterancaman dan kepunahan spesies tumbuhan tertinggi di dunia. Saat ini tercatat sekitar 240 spesies tanaman dinyatakan langka, diantaranya banyak yang merupakan spesies tanaman budidaya. Selain itu, sekitar 36 spesies pohon di Indonesia dinyatakan terancam punah, termasuk kayu ulin di Kalimantan Selatan, sawo kecik di Jawa Timur, Bali Barat, dan Sumbawa, kayu hitam di Sulawesi, dan kayu pandak di Jawa serta ada sekitar 58 spesies tumbuhan yang berstatus dilindungi.

Berbagai faktor dapat mengancam kepunahan keanekaragaman hayati ini, diantaranya : kerusakan habitat, kerusakan ekosistem, polusi, perubahan iklim global, eksploitasi berlebihan, hadirnya spesies asing (invasive alien species) dan munculnya gangguan penyakit (CBD 2014). Dalam era globalisasi saat ini, dimana terjadi peningkatan arus lalu lintas barang dan manusia tanpa mengenal batas antar negara melalui kegiatan ekspor, impor serta perdagangan antar wilayah (domestik) membuka peluang bagi kemungkinan masuk dan tersebarnya hama dan penyakit hewan serta organisme pengganggu tumbuhan yang berbahaya atau menular yang dapat merusak sumberdaya alam hayati karena tanah air Indonesia atau sebagian pulau-pulau di Indonesia masih bebas dari berbagai hama dan penyakit hewan serta organisme pengganggu tumbuhan tersebut. Untuk mencegah masuknya hama dan penyakit hewan ke wilayah Negara Republik Indonesia serta mencegah tersebarnya dari suatu area ke area lain dan mencegah keluarnya dari wilayah Republik Indonesia, maka peran dan fungsi karantina pertanian sebagai garda terdepan perlindungan pertanian Indonesia dan sebagai technical barrier dalam perdagangan internasional perlu ditingkatkan. Pemeriksaan dan sertifikasi karantina pertanian bertujuan untuk melindungi kelestarian sumberdaya alam hayati hewan dan tumbuhan dari ancaman hama dan penyakit hewan karantina atau organisme pengganggu tumbuhan karantina serta gangguan terhadap keamanan pangan. Dalam sertifikat karantina akan dinyatakan bahwa hewan atau tumbuhan atau produk yang akan dilalulintaskan telah dilakukan pemeriksaan dan dinyatakan dalam keadaan sehat, tidak terjangkit penyakit menular dan tidak membawa organisme berbahaya yang dapat mengancam kesehatan manusia/hewan/tumbuhan lain. Masuk dan tersebarnya agen penyakit ini dapat mengganggu produksi dan produkifitas pertanian di Indonesia. Menurut Dirgahayu et al. (2012) kegagalan panen (puso) tanaman padi salah satunya adalah adanya organisme pengganggu tanaman (OPT).

Badan Karantina Pertanian (2016) melaporkan bahwa pada tahun 2016 telah melakukan sertifikasi karantina komoditas tumbuhan dan produknya, dengan total frekuensi 688084 kali dan melakukan sertifikasi karantina komoditas hewan dan produknya dengan total frekuensi 580628 kali, sehingga secara keseluruhan total sertifikasi adalah 1268712 kali. Menurut Baraniah (2014) keberhasilan kegiatan importasi huwan dan atau produk hewan untuk terbebas dari agen penyakit hewan menular, bebas dari residu dan tidak mengganggu kesehatan dan ketentraman batin masyarakat ditentukan oleh kemampuan pelaksana, sarana, pendanaan, peran dan partisipasi masyarakat khususnya pelaku usaha agar turut bertanggung jawab atas tidak tercemarnya atau tidak berbahayanya komoditas yang dilalulintaskan.

Untuk itu dibutuhkan suatu strategi bagaimana mengubah perilaku pengguna jasa agar lebih peduli, sadar dan patuh untuk turut serta mendukung perlindungan sumberdaya alam hayati. Berdasarkan latar belakang yang telah diuraikan diatas, maka dapat dirumuskan permasalahan yang akan dikaji dalam penelitian ini yaitu: Bagaimana perilaku pengguna jasa karantina pertanian dalam mendukung terciptanya perlindungan sumberdaya alam hayati melalui kegiatan perkarantinaan.

\section{METODE}

\section{Tempat dan Waktu}

Penelitian ini dilakukan di tiga lokasi yang menjadi sasaran penelitian, yaitu: Balai Besar Karantina Pertanian Tanjung Priok, Balai Besar Karantina Pertanian Soekarno Hatta, dan Balai Besar Karantina Pertanian Makassar. Penelitian dilaksanakan dari bulan Januari-Maret 2017.

\section{Metoda Pengumpulan dan Analisis Data}

Responden pada penelitian ini adalah pengguna jasa karantina pertanian yang diambil secara purpossive random sampling, yaitu wawancara dan pengisian kuisioner dengan jumlah 150 responden. Menurut Santoso (2015), jumlah sampel sebanyak 100-200 responden pada umumnya dapat diterima sebagai sampel yang representatif pada analisis Structural Equation Modelling (SEM). Metode analisis yang digunakan adalah: 


\section{Customer Satisfaction Index (CSI)}

CSI digunakan untuk mengukur tingkat kepuasan pengguna jasa secara menyeluruh. Menurut Tjiptono dan Chandra (2016) model kualitas layanan yang banyak dijadikan acuan dalam penelitian manajemen dan pemasaran jasa adalah SERVQUAL (singkatan dari service quality) yang dikembangkan oleh Parasuraman et al. (1988) menggunakan lima dimensi utama kualitas layanan yaitu : kehandalan, daya tanggap, jaminan, empati, dan bukti fisik.

Tabel 1 Variabel dan Indikator Pengukuran Kualitas Layanan

\begin{tabular}{ll}
\hline Variabel & \multicolumn{1}{c}{ Indikator } \\
\hline Kehandalan & Menyediakan pelayanan jasa sesuai yang dijanjikan \\
& Kemampuan petugas dapat diandalkan dalam menyelesaikan masalah \\
& Pelayanan disampaikan secara benar sejak pertama kali \\
& Menyampaikan pelayanan sesuai dengan waktu yang dijanjikan \\
& Menyimpan catatan/dokumen tanpa kesalahan \\
Daya Tanggap & Menyampaikan ke pengguna jasa tentang kepastian waktu penyelesaian \\
& penerbitan sertifikat \\
& Layanan yang segera dan cepat \\
& Kesediaan petugas untuk membantu pengguna jasa \\
& Kesiapan petugas untuk menanggapi permintaan pengguna jasa \\
Jaminan & Petugas dapat menumbuhkan rasa percaya bagi pengguna jasa \\
& Membuat pengguna jasa merasa aman selama proses layanan \\
& Petugas selalu bersikap sopan \\
Empati & Petugas mampu menjawab pertanyaan pengguna jasa \\
& Memberikan perhatian individual kepada pengguna jasa \\
& Petugas memahami kebutuhan pengguna jasa \\
& Waktu pelayanan (jam kantor) yang nyaman \\
Bukti Fisik & Kesesuaian antara pelayanan dan prosedur yang ada \\
& Peralatan modern \\
& Fasilitas yang memadai dan berdaya tarik \\
& Petugas yang rapih, berseragam dan profesional \\
& Pajangan produk yang berkaitan dengan jasa yang berdaya tarik \\
\hline
\end{tabular}

Sumber: diolah dan disesuaikan dari Parasuraman et al. (1994)

\section{Analisis Regresi Linier Berganda}

Analisis ini digunakan untuk mengetahui seberapa besar pengaruh variabel bebas seperti kehandalan (X1), daya tanggap (X2), jaminan (X3), empati (X4), bukti fisik (X5) terhadap variabel terikat kepuasan konsumen (Y).

Persamaan regresi yang dipakai adalah :

$$
\begin{array}{ccl}
\mathrm{Y}=\mathrm{a}+\mathrm{b} 1 & \mathrm{X} 1+\mathrm{b} 2 \mathrm{X} 2+\mathrm{b} 3 \mathrm{X} 3+\mathrm{b} 4 \mathrm{X} 4+\mathrm{b} 5 \mathrm{X} 5+\mathrm{e} \\
\text { di mana: } & \\
- & \mathrm{Y} & =\text { Kepuasan pengguna jasa } \\
- & \mathrm{a} & =\text { Konstanta } \\
- & \mathrm{b} 1 & =\text { Koefisien regresi variabel X1 } \\
\text { - } & \mathrm{b} 2 & =\text { Koefisien regresi variabel X2 } \\
- & \mathrm{b} 3 & =\text { Koefisien regresi variabel X3 } \\
\text { - } & \mathrm{b} 4 & =\text { Koefisien regresi variabel X4 } \\
- & \mathrm{b} 5 & =\text { Koefisien regresi variabel X5 } \\
- & \mathrm{e} & =\text { error/ variabel pengganggu }
\end{array}
$$




\section{Structural Equation Modelling (SEM)}

Menurut Santoso (2015) Structural Equation Modeling (SEM) adalah alat analisa statistik dimana penyusunan model dan cara kerjanya merupakan gabungan antara analisis faktor dan analisis regresi. Metode SEM merupakan perkembangan dari analisis jalur (path analysis) dan regresi berganda (multiple regression) yang sama-sama merupakan bentuk model analisis multivariat (multiple regression). SEM dalam penelitian ini digunakan untuk menganalisis sejauh mana pengaruh persepsi dan kualitas layanan terhadap perilaku partisipasi dan kepatuhan pengguna jasa dalam kaitannya terhadap perlindungan sumberdaya alam melalui kegiatan perkarantinaan. Dalam penelitian ini yang akan diukur adalah bagaimana persepsi pengguna jasa terhadap karantina pertanian dilihat dari segi manfaat kekarantinaan pertanian (ekonomi, ekologi dan sosial) serta dari segi internal (SDM, sarana prasarana, serta alur dan prosedur) yang secara rinci dapat dilihat pada Tabel 2.

Tabel 2 Variabel dan Indikator Pengukuran Persepsi

\begin{tabular}{ll}
\hline Variabel & Indikator \\
\hline Manfaat Ekologi & $\begin{array}{l}\text { Peran Karantina dalam mencegah masuk dan tersebarnya hama dan organisme } \\
\text { pengganggu }\end{array}$ \\
& $\begin{array}{l}\text { Karantina berperan menjaga keanekaragaman hayati } \\
\text { Karantinne dapat mencegah paparan spesies asing invasif }\end{array}$ \\
Manfat Ekonomi & $\begin{array}{l}\text { Peran karantina dalam percepatan ekspor komoditas pertanian } \\
\text { Peran karantina dalam mengaga dan meningkatkan komoditas pertanian }\end{array}$ \\
& $\begin{array}{l}\text { Karantina sebagai technical barrier impor komoditas pertanian } \\
\text { Terlindunginya masyarakat dari penyakit zoonosis }\end{array}$ \\
Manfaat Sosial & $\begin{array}{l}\text { Terjaganya kesehatan masyarakat dan lingkungan } \\
\text { Menghindarkan keresahan akan terjadinya wabah penyakit }\end{array}$ \\
SDM & $\begin{array}{l}\text { Apakah jumlah dan mutu SDM telah mencukupi } \\
\text { Sarana Prasarana }\end{array}$ \\
Alur & Penah sarana prasarana sudah memadai dan memenuhi harapan \\
prosedur & Pengetahuan dan pemahaman alur dan prosedur \\
\hline
\end{tabular}

\section{HASIL DAN PEMBAHASAN}

\section{Analisis Tingkat Kepuasan Pengguna Jasa dan Faktor-Faktor yang Mempengaruhi}

Hasil penelitian menunjukkan nilai CSI sebesar $78.26 \%$ yang nilainya berada pada interval $66 \%$ - $80.99 \%$, berarti pengguna jasa merasa "puas" terhadap kinerja yang dilakukan oleh karantina pertanian, tetapi belum sampai pada tingkat sangat puas. Pengukuran indeks kepuasan harus dilakukan secara berkelanjutan agar dapat diketahui bahwa apa yang dilakukan sesuai dengan harapan pengguna jasa, karena hal ini akan berdampak pada tingkat partisipasi dan kepatuhan pengguna jasa. Lovelock et al. (2012) mengemukakan bahwa mutu layanan merupakan tingkatan kondisi baik buruknya sajian yang diberikan oleh penyedia jasa dalam rangka memuaskan konsumen dengan cara memberikan pelayanan jasa yang melebihi harapan konsumen.

Berdasarkan hasil analisis Regresi Linier Berganda diperoleh nilai Adjusted $\mathrm{R}^{2}$ sebesar $99.8 \%$, artinya kehandalan, daya tanggap, jaminan, empati dan bukti fisik mampu menjelaskan kepuasan pengguna jasa, sisanya diterangkan oleh faktor lain yang tidak diteliti. Nilai adjusted $\mathrm{R}^{2}$ dapat dilihat pada Tabel 3 .

Dari hasil uji simultan analisis regresi linier berganda (tabel 4) didapatkan bahwa ada pengaruh secara bersama-sama terhadap kepuasan atau minimal satu variabel bebas yang berpengaruh terhadap kepuasan dengan nilai probabilitas sebesar 0.000 yang nilainya lebih kecil dari alpha yaitu sebesar $5 \%$.

Tabel 3. Hasil uji koefisien determinasi

\begin{tabular}{cccccc}
\hline \multicolumn{2}{l}{ Model Summary } \\
\hline Model & $R$ & $R$ Square & $\begin{array}{c}\text { Adjusted } R \\
\text { Square }\end{array}$ & Std. Error of the Estimate & Durbin-Watson \\
\hline 1 & $.999^{\text {a }}$ & .998 & .998 & .98274 & 1.954 \\
\hline
\end{tabular}

a. Predictors: (Constant), bukti fisik, daya tanggap, kehandalan, empati, jaminan

b. Dependent Variable: kepuasan 
Tabel 4 Uji Simultan

\begin{tabular}{llrrrrr}
\hline \multicolumn{7}{c}{ ANOVA $^{\mathrm{a}}$} \\
\hline Model & & Sum of Squares & df & Mean Square & F & \multicolumn{1}{c}{ Sig. } \\
1 & Regression & 85435.867 & 5 & 17087.173 & 17692.487 & $.000^{\mathrm{b}}$ \\
& Residual & 139.073 & 144 & .966 & & \\
& Total & 85574.940 & 149 & & & \\
\hline
\end{tabular}

a. Dependent Variable : kepuasan

b. Predictors: (Constant). : bukti fisik, daya tanggap, kehandalan, empati, jaminan

Kemudian uji $\mathrm{T}$ (parsial) untuk mengetahui variabel bebas mana yang berpengaruh secara parsial terhadap kepuasan pengguna jasa Uji T menghasilkan model regresi sebagai berikut :

Kepuasan $=-0.286+1.931$ Kehandalan +2.070 Daya Tanggap +1.903 Jaminan +2.188 Empati +0.937 Bukti Fisik

Berdasarkan perhitungan uji $\mathrm{T}$ (parsial) dapat diketahui bahwa variabel empati mempunyai nilai koefisien (standardized coefficients) lebih besar daripada koefisien variabel lainnya sehingga hal ini menunjukkan bahwa variabel empati merupakan variabel yang paling berpengaruh terhadap kepuasan pengguna jasa. Semakin baik empati maka akan semakin meningkatkan kepuasan pengguna jasa. Tetapi variabel lainnya juga mempunyai pengaruh positif dan signifikan terhadap kepuasan pengguna jasa. Rahayu (2017) yang melakukan penelitian pada kualitas pelayanan Hotel Gumaya Semarang menyatakan bahwa variabel kualitas pelayanan dalam kelima dimensinya memiliki pengaruh yang positif dan signifikan terhadap kepuasan konsumen. Hal ini disebabkan dengan pemberian pelayanan yang berkualitas, maka hal tersebut akan menciptakan kepuasan dalam diri konsumen. Mulyawan (2015) menyatakan bahwa tinggi rendahnya kepuasan mahasiswa terhadap layanan jasa pendidikan di STMIK Mardira Indonesia Bandung dipengaruhi oleh bukti fisik, empat, kehandalan, daya tanggap dan kepastian. Khan (2014) menyatakan bahwa kualitas pelayanan sektor perbankan di Pakistan dengan berbagai atributnya mempunyai pengaruh signifikan dan positif terhadap kepuasan dan loyalitas nasabah.

\section{Persepsi, Kualitas Layanan, dan Pengaruhnya terhadap Perilaku Partisipasi dan Kepatuhan Pengguna Jasa}

Persepsi dapat didefinisikan sebagai proses dimana individu-individu mengorganisasikan dan menafsirkan kesan indera mereka agar memberi makna kepada lingkungan mereka (Robbins dan Stephen, 2008). Menurut Tampubolon (2008) persepsi adalah gambaran seseorang tentang sesuatu obyek yang menjadi fokus permasalahan yang sedang dihadapi. Kotler dan Keller (2007) mendefinisikan persepsi adalah proses yang digunakan individu untuk memilih, mengorganisasi dan menginterpretasi masukan informasi guna menciptakan gambaran dunia yang memiliki arti. Model SEM yang digunakan dalam penelitian ini dijalankan menggunakan perangkat lunak Linear Structural Relationship (LISREL).

Menurut Hair et al. (2006), tidak ada uji statistik tunggal untuk mengukur atau menguji keseluruhan model. Oleh karena itu digunakan beberapa ukuran kriteria kesesuaian yang saling mendukung model penelitian yang telah ditetapkan. Hasil pengolahan pengujian goodness of fit menunjukkan model sudah baik menggunakan pengujian chi square ( $p$-value $0.34147 \geq 0.05$ ). Pengujian lain menggunakan kriteria Root Means Square Error of Approximation (RMSEA) dengan nilai $0.018 \leq 0.08$, Goodness of Fit Index (GFI), Normed Fit Index (NFI) dan Comparative Fit Index (CFI) menghasilkan nilai $\geq 0.90$ menunjukkan bahwa model yang dihasilkan sudah sesuai atau fit. Hasil uji kesesuaian model selengkapnya pada Tabel 5. 
Tabel 5 Uji Kesesuaian Model (Goodness of Fit)

\begin{tabular}{cccc}
\hline Goodness-of-Fit & Cutt-off-Value & Hasil & Kesimpulan \\
\hline $\mathrm{X}^{2}$ - Chi-square & Diharapkan kecil & 122.67 & goodness of fit \\
Significance & $\geq 0.05$ & $\mathrm{P}=0.34147$ & \\
RMSEA & $\leq 0.08$ & 0.018 & goodness of fit \\
GFI & Mendekati 1 & 0.98 & goodness of fit \\
NFI & Mendekati 1 & 1.00 & goodness of fit \\
CFI & Mendekati 1 & 1.00 & goodness of fit \\
\hline
\end{tabular}

Dari hasil analisis dengan metoda SEM, didapatkan nilai faktor muatan model, yaitu koefisien yang menunjukkan seberapa besar tingkat kontribusi relatif dari masing-masing variabel indikator dalam membentuk variabel laten. Semakin besar nilainya menunjukkan semakin besar kontribusinya dalam membentuk variabel laten. Nilai muatan model dalam penelitian ini ditunjukkan oleh Gambar 1.

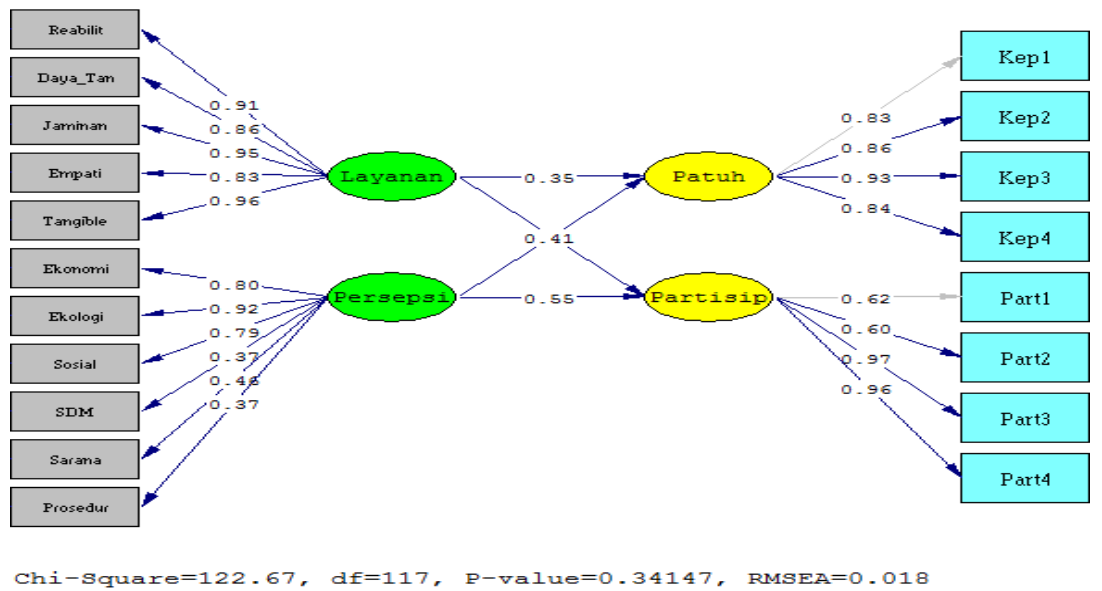

Gambar 1 Estimasi Parameter Model Struktural

Keterangan :

Kep 1 : pemahaman syarat dan ketentuan lalu lintas komoditas

Kep 2 : pengisian dokumen secara baik dan benar

Kep 3 : melengkapi syarat dan prosedur

Kep 4 : pembayaran sesuai dengan tarif yang dibebankan

Part 1 : pencarian informasi tentang karantina pertanian

Part 2 : keaktifan mengikuti kegiatan sosialisasi/public hearing

Part 3 : penyebarluasan berita positif terkait karantina pertanian

Part 4 : berpartisipasi dalam pengawasan lalu lintas komoditas pertanian

Hasil analisis dengan model SEM memperlihatkan bahwa variabel yang terkuat dalam menjelaskan kualitas layanan berturut-turut adalah bukti fisik (0.96), jaminan (0.95), kehandalan (0.91), daya tanggap (0.86), dan empati (0.83). Hal ini sesuai dengan penelitian Ardiyan (2017) yang menyimpulkan bahwa diantara kelima dimensi penentu kualitas layanan berdasarkan nilai pentingnya menurut pelanggan adalah bukti fisik, selanjutnya berturut-turut jaminan, kehandalan, daya tanggap dan empati. Sedangkan variabel yang paling menggambarkan persepsi pengguna jasa tentang karantina pertanian adalah tentang manfaat ekologi (0.92), kemudian berturut-turut adalah manfaat ekonomi (0.80), manfaat sosial (0.79), sarana prasarana (0.46), SDM dan tata kerja (0.37). Hal ini sejalan dengan penelitian Ruslin (2014) yang menyatakan bahwa wacana ekologis harus terus menerus dikonstruksikan untuk meminimalisir kerusakan lingkungan yang merupakan titipan generasi mendatang. 


\section{Pengujian Hipotesis}

Hasil pengujian hipotesis yang diajukan dalam penelitian ini secara ringkas ditunjukkan pada tabel 4. Semua variabel mempunyai pengaruh signifikan terhadap perilaku pengguna jasa, tetapi variabel yang paling berpengaruh adalah persepsi pengguna jasa terhadap karantina pertanian. Perilaku adalah sikap yang berujung kepada perbuatan (Ahmadi, 2007). Perilaku pengguna jasa karantina pertanian adalah tindakan yang berhubungan dengan pemanfaatan jasa karantina pertanian oleh individu atau institusi untuk kelancaran proses lalu lintas barang di tempat-tempat pemasukan dan pengeluaran. Dalam penelitian ini, perilaku yang dianalisis adalah perilaku kepatuhan dan partisipasi pengguna jasa pertanian.

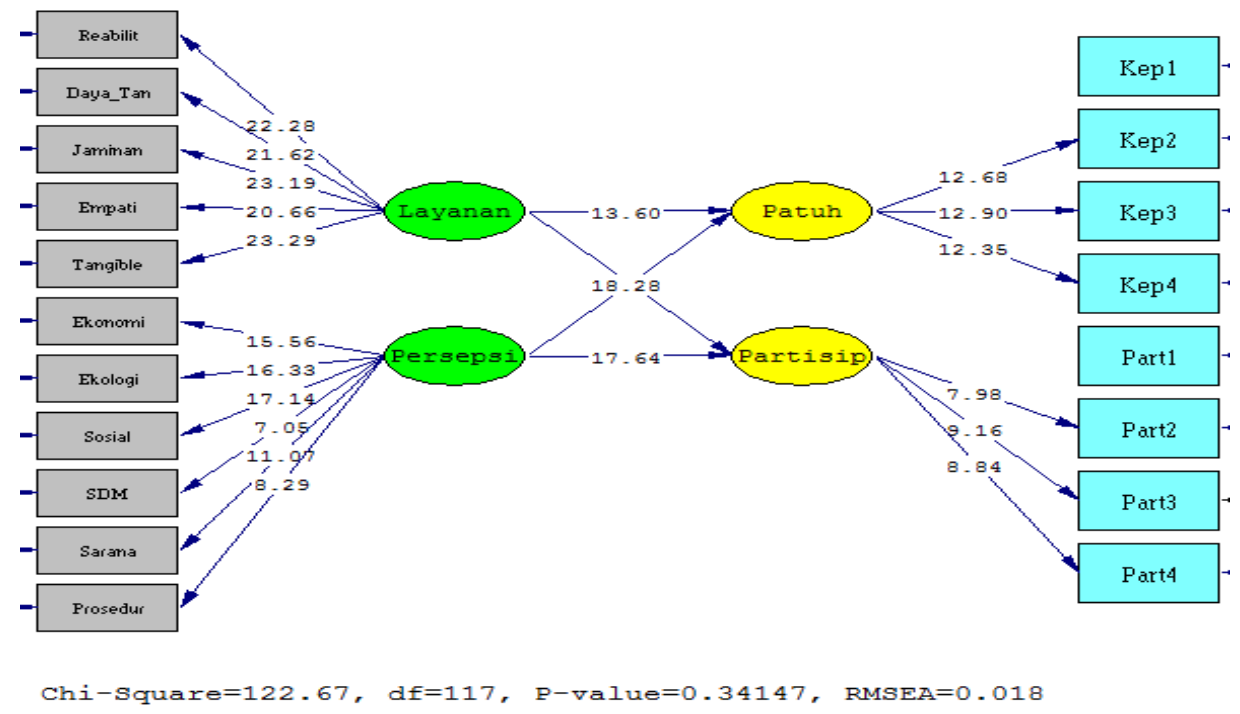

Gambar 2 Uji T

Berdasarkan hasil uji signifikansi t pada gambar 2 dapat dilihat bahwa tingkat partisipasi dan kepatuhan lebih dipengaruhi oleh persepsi pengguna jasa dibandingkan oleh kualitas layanan. Tabel 6 menjelaskan secara lengkap hipotesis yang telah diuji dengan SEM.

Tabel 6 Hasil estimasi regresi SEM

\begin{tabular}{llllll}
\hline H & Path & Est. & S.E & $\mid$ t-hit $\mid>\mathbf{1 . 9 6}$ & Ket. \\
\hline H1 & Kualitas layanan $\rightarrow$ kepatuhan & 0.35 & 0.025 & 13.60 & Signifikan \\
H2 & Persepsi $\rightarrow$ kepatuhan & 0.52 & 0.036 & 14.39 & Signifikan \\
H3 & Kualitas layanan $\rightarrow$ partisipasi & 0.41 & 0.022 & 18.28 & Signifikan \\
H4 & Persepsi $\rightarrow$ partisipasi & 0.55 & 0.031 & 17.64 & Signifikan \\
\hline
\end{tabular}

Hipotesis 1 menyatakan kualitas layanan berpengaruh positif terhadap perilaku patuh pengguna jasa terhadap karantina pertanian (kepatuhan). Dari hasil pengolahan diperoleh koefisien estimasi sebesar 0.35 yang artinya semakin baik kualitas layanan akan semakin baik tingkat kepatuhan pengguna jasa dan sebaliknya. Hasil ini menunjukkan bahwa hipotesis teori yang diajukan terbukti dengan nilai thitung sebesar $13.60>\mathrm{t}-$ table 1.96 yang artinya Ho ditolak sehingga dapat disimpulkan bahwa terdapat pengaruh positif dari kualitas layanan terhadap tingkat kepatuhan secara nyata. Supadmi (2009) menyatakan bahwa kualitas pelayanan dengan memberikan keamanan, kenyamanan, kelancaran dan kepastian hukum yang dapat dipertanggungjawabkan dapat meningkatkan kepatuhan wajib pajak dalam memenuhi kewajiban perpajakannya. Asbar (2014) dalam penelitiannya terhadap tingkat kepatuhan wajib pajak orang pribadi juga menyatakan bahwa kualitas layanan berpengaruh terhadap kepatuhan wajib pajak. Fuadi (2013) menyatakan bahwa kualitas pelayanan dan sanksi perpajakan berpengaruh positif terhadap kepatuhan wajib pajak Usaha Mikro Kecil dan Menengah UMKM.

Hipotesis 2 menyatakan persepsi pengguna jasa berpengaruh positif terhadap perilaku patuh terhadap karantina pertanian (kepatuhan). Dari hasil pengolahan diperoleh koefisien estimasi sebesar 0.52 yang artinya semakin baik persepsi pengguna jasa tentang karantina pertanian akan semakin baik tingkat kepatuhannya dan 
sebaliknya. Hasil ini menunjukkan bahwa hipotesis teori yang diajukan terbukti dengan nilai hitung sebesar $14.39>$ t-table 1.96 yang artinya Ho ditolak sehingga dapat disimpulkan bahwa terdapat pengaruh positif dari persepsi pengguna jasa tentang karantina pertanian terhadap tingkat kepatuhan pengguna jasa secara nyata. Perilaku patuh pengguna jasa dapat dicerminkan melalui pemahaman dan implementasi semua syarat, peraturan, alur dan tata kerja karantina dalam melalulintaskan komoditas serta tanggung jawab dalam kelengkapan, kebenaran, keabsahan dan kesesuaian dokumen persyaratan dan kesanggupan membayar biaya pelayanan sesuai dengan tarif Penerimaan Negara Bukan Pajak (PNBP) yang berlaku. Harihanto (2001) menjelaskan perilaku adalah hasil dari persepsi, dan persepsi yang salah bisa menimbulkan perilaku yang salah.

Hipotesis 3 menyatakan kualitas layanan berpengaruh positif terhadap tingkat partisipasi pengguna jasa dalam setiap kegiatan penyelenggaraan perkarantinaan. Dari hasil pengolahan diperoleh koefisien estimasi sebesar 0.41 yang artinya semakin baik kualitas layanan akan semakin baik tingkat partisipasi pengguna jasa dan sebaliknya. Hasil ini menunjukkan bahwa hipotesis teori yang diajukan terbukti dengan nilai thitung sebesar 18.28 > t-table 1.96 yang artinya Ho ditolak sehingga dapat disimpulkan bahwa terdapat pengaruh positif dari kualitas layanan terhadap tingkat partisipasi pengguna jasa secara nyata. Sulistyowati (2015) dalam penelitiannya menyimpulkan bahwa secara simultan terdapat pengaruh pelayanan, kinerja pengurus dan motivasi berkoperasi pada Koperasi Pegawai Republik Indonesia Eka Karya terhadap partisipasi anggota sebesar $58.2 \%$.

Hipotesis 4 menyatakan persepsi berpengaruh positif terhadap tingkat partisipasi pengguna jasa. Dari hasil pengolahan diperoleh koefisien estimasi sebesar 0.55 yang artinya semakin baik persepsi pengguna jasa akan semakin baik partisipasi pengguna jasa dan sebaliknya. Hasil ini menunjukkan bahwa hipotesis teori yang diajukan terbukti dengan nilai thitung sebesar $17.64>$ t-tabel 1.96 yang artinya Ho ditolak sehingga dapat disimpulkan bahwa terdapat pengaruh positif dari persepsi pengguna jasa terhadap partisipasi secara nyata. Partisipasi pengguna jasa dicerminkan melalui tingkat keterlibatan pengguna jasa dalam setiap kegiatan perkarantinaan (sosialisasi, public hearing, dll) serta keturutsertaannya dalam menyebarluaskan dan mensosialisasikan tentang karantina pertanian terhadap pihak lain. Kartikawati (2014) menyatakan bahwa tingkat pengenalan (awareness) masyarakat terhadap nama Badan Karantina Pertanian mencapai 59\%, namun tingkat pengenalan (awareness) belum berarti secara otomatis sama dengan tingkat pengetahuan (knowledge) dari responden akan tugas dan fungsi Badan Karantina Pertanian, sehingga diperlukan program yang bersifat memberikan informasi dan edukasi kepada masyarakat akan tugas dan fungsi Badan Karantina Pertanian.

\section{SIMPULAN}

Nilai CSI berada yang pada kisaran puas harus dijadikan sebagai landasan untuk melakukan upaya yang lebih baik lagi agar nilai tersebut dapat ditingkatkan sehingga masuk dalam kisaran sangat puas. Area bandar udara atau pelabuhan merupakan area dengan tingkat kerumitan yang tinggi karena melibatkan berbagai pihak dan pengguna jasa membutuhkan kecepatan dalam hal pelayanan. Pengguna jasa menganggap bahwa waktu sangat erat kaitannya dengan beban dwelling time dan beban biaya yang ditanggung oleh pengguna jasa. Kecepatan pelayanan dan kesiapan petugas dianggap hal yang sangat penting dan perlu ditingkatkan kinerjanya.

Berdasarkan hasil analisis SEM menunjukkan bahwa persepsi lebih berpengaruh terhadap perilaku partisipasi dan kepatuhan pengguna jasa dibandingkan kualitas layanan. Oleh karena itu, perbaikan harus diprioritas terhadap peningkatan persepsi pengguna jasa yang kemudian diikuti dengan upaya meningkatkan kualitas pelayanan. Pembentukan persepsi yang positif tentang karantina pertanian akan meningkatkan partisipasi dan kepatuhan pengguna jasa karena pengguna jasa merasa yakin bahwa dengan memanfaatkan pelayanan karantina pertanian akan membawa dampak positif dalam meningkatkan perlindungan sumberdaya alam dan dapat turut serta mendukung percepatan ekspor komoditas pertanian. 


\section{DAFTAR PUSTAKA}

Ahmadi AH. 2007. Psikologi Sosial. Jakarta: Rineka Cipta.

Ardiyan F. 2017. Analisis pengaruh tingkat kualitas pelayanan jasa puskesmas terhadap kepuasan pasien. Jurnal Manajemen Universitas Pandanaran. 3(3):1-7.

Asbar AK. 2014. Pengaruh tingkat kepuasan pelayanan. pemahaman perpajakan, keadilan perpajakan, sanksi perpajakan terhadap tingkat kepatuhan wajib pajak orang pribadi pada kpp pratama senapelan pekanbaru. Jurnal Online Mahasiswa Fakultas Ekonomi Universitas Riau. 1(2), pp. 1-15.

Baraniah MA. 2014. Pegangan Memahami Importasi Hewan dan Produknya. Jakarta: Penebar Swadaya.

Dirgahayu et al. 2012. Deteksi kondisi ketahanan pangan beras menggunakan permodelan spasial kerentanan pangan. Jurnal Pengelolaan Sumberdaya Alam dan Lingkungan. 2(2): 85-93.

Fuadi. 2013. Pengaruh Kualitas Pelayanan Petugas Pajak, Sanksi Perpajakan dan Biaya Kepatuhan Pajak terhadap Kepatuhan Wajib Pajak UMKM.

Hair JFJ, Black WC, Babin BJ, Anderson RE, Tatham RL. 2006. Multivariate Data Analysis. United States: Pearson Education, Inc.

Harihanto. 2001. Persepsi, Sikap dan Perilaku Masyarakat terhadap Air Sungai: Kasus Di DAS Kaligarang Jawa Tengah. Disertasi. Bogor: Sekolah Pascasarjana, Institut Pertanian Bogor.

Kartikawati E. 2014. Formulasi strategi komunikasi karantina pertanian menggunakan audit komunikasi. Jurnal Masyarakat Telematika dan Informasi. 5(2): 127-152.

Khan MM. 2014. Impact of Service Quality on Customer Satisfaction and Customer Loyalty; Evidence from Banking Sector. Pakistan Journal of Commerce and Social Sciences. 8(2): 331-354.

Kotler P, Keller KL. 2007. Manajemen Pemasaran. Klaten: PT Macanan Jaya Cemerlang.

Kusmana C, Hikmat A. 2015. Keragaman Hayati Flora di Indonesia. Jurnal Pengelolaan Sumberdaya Alam dan Lingkungan. 5(2): 187-198.

Lovelock C, Wirtz J, Mussry J. 2012. Pemasaran Jasa. Dian W, Devri BP, Penerjemah. Penerbit Erlangga, Jakarta. Terjemahan dari Services Marketing. Ed ke-7.

Mac Kinnon K. 1992. Nature's Treasurehouse the Wildlife of Indonesia. Jakarta: PT Gramedia Pustaka Utama.

Mittermeier CG. 1997. Megadiversity Country. Mexico City: Agrupaciaon Sierra Madre.

Mulyawan A. 2015. Determinan kualitas layanan akademik di STMIK Mardira Indonesia Bandung. Jurnal Computech dan Bisnis. 8(1):13-24.

Parasuraman A, Zeithaml VA, Berry LL. 1988. Serviqual: A multiple item scale for measuring consumer perception of service quality. Journal of Retailing. 64: 12-40.

Parasuraman A, Zeithaml VA, Berry LL. 1994. Alternative scales for measuring service quality: A comparative assessment based on psychometric and diagnostic criteria. Journal of Retailing. 70(3): 201230.

Rahayu. 2017. Analisis tingkat kepuasan konsumen terhadap kualitas pelayanan hotel (Studi Kasus pada Hotel Gumaya di Semarang). Jurnal Universitas Pandanaran. 3(3): pp.1-8.

Robbins, Stephen P. 2008. Perilaku Organisasi. Jakarta: Penerbit Salemba Empat.

Ruslin TI. 2014. Lingkungan hidup dan liberalisasi perdagangan global. Jurnal Politik Profetik UIN Allaudin. 3(1).

Santoso S. 2015. Structural Equation Modelling; Konsep dan Aplikasi dengan AMOS 22. Jakarta: PT Elex Media Komputindo.

Secretariat of the Convention ob Biological Diversity. 2014. Global Biodiversity Outlook 4. Montreal: 155 pages. 
Sulistyowati T. 2015. Pengaruh pelayanan, kinerja pengurus koperasi dan motivasi berkoperasi terhadap partisipasi anggota Koperasi Pegawai Republik Indonesia (KPRI) Eka Karya Kendal. Economic Education Analysis Journal. 4(2):496-508.

Supadmi N. 2009. Meningkatkan kepatuhan wajib pajak melalui kualitas pelayanan. Jurnal Ilmiah dan Akutansi Bisnis. 4(2).

Tampubolon MP. 2008. Perilaku. Bogor: Ghalia Indonesia.

Tjiptono F, Chandra G. 2016. Service, Quality dan Satisfaction. Yogyakarta: Penerbit ANDI Yogyakarta. 